

\section{Por que ler?}

RESUMO: Num real construído em cima da escrita e suas representações como é o nosso, é não só importante saber ler, mas também criar o hábito da leitura. Porém, por que ler? O que ler? Este é como se alimentar e fazer da leitura uma metabolização apropriante. Isso é desenvolvido nos seguintes tópicos: O leitor sem leitura; ler como escuta; o leitor com a cabeça cheia; ler e escrever; ser poeta; o leitor com a cabeça bem feita; o leitor e a sabedoria; a leitura e a vida; a leitura e a memória; a leitura e a morte.

PALAVRAS-CHAVE: leitura, sabedoria, memória, morte, ser.

\section{Por que ler?}

Eis uma pergunta muito importante na nossa vida. E, talvez, a melhor resposta ainda esteja numa outra pergunta: Por que comer?

Eu penso que a comparação do ler com o ato de comer é muito direta e fácil de entender. Hoje todos sabem que temos um código genético que "comanda" a formação de nosso corpo, de nossas tendências orgânicas, mas não "comanda" a nossa formação cultural, o nosso crescimento intelectual, o nosso desenvolvimento emocional, as nossas ações éticas, ou seja, não "comanda" aquilo que chamamos com muita propriedade: nosso ser (sem as separações tradicionais e metafísicas entre corpo e alma, orgânico e não-orgânico. O ser que somos é sempre um todo inseparável). A palavra comanda entre aspas indica exatamente o mistério dessa união que nos desafia. A linguagem do ser é mais do que um código. Nós somos mais do que um código.

Para termos um organismo bem desenvolvido é necessário comer. Mas o quê? Uma alimentação nutritiva e adequada propicia um bom desenvolvimento físico, uma boa aparência e saúde. Se não nos alimentamos, morremos. Se nos alimentamos mal, temos problemas sérios de saúde mental e física. A capacidade mental fica seriamente afetada. Porém, se comemos muito e mal temos igualmente problemas de saúde: a obesidade com todas as suas maléficas conseqüências. Isso é sabido de todos. Porém, notemos algo muito importante. O que comemos passa por um metabolismo que transforma o alimento no que somos, mental e fisicamente. Ainda é importante lembrar uma coisa. Todos os seres vivos têm um código genético, mas há algo no homem que o distância e
Manuel Antônio de Castro

Doutor em Letras

Professor Titular de Poética da Facul-

dade de Letras da UFRJ

manuel@ufrj.br 
diferencia desse "comando" do código genético. O que é? O ser humano faz da necessidade de comer algo mais do que satisfazer a uma necessidade. Ele a transfigura num ato livre e criativo. Como? Fazendo do comer uma "arte" culinária. Todos os povos em todos os tempos e lugares tiveram uma arte culinária, fazendo do viver uma arte de sabor e sabedoria. Isto não está inscrito no código genético e nem qualquer análise científica pode detectar. Onde está?

É esta "arte criativa" que permite até ler e investigar o código genético. Ela 1he é dada. Mas ele precisa desenvolvê-la, cultivá-la, alimentá-la. Como? Através da leitura. A leitura, nesse sentido, será o ato livre pelo qual nos alimentamos para podermos chegara ser o que somos. Hoje, em nossa sociedade, sem esse alimento propiciado pela leitura não será possível de jeito nenhum o crescimento normal, a inclusão social, a aquisição de uma profissão, o livre exercício da cidadania, a realização do que somos. Leitura é alimento. E na leitura deve ocorrer o mesmo processo do alimento físico: um metabolismo intelectual pelo qual devemos transformar o que os outros dizem e escrevem em algo nosso, incorporado a nosso ser. Isso pressupõe que o ler não deve consistir em decorar nem em repetir o que os outros dizem. Leitura é alimento metabolizado, apropriado.

\section{O leitor sem leitura}

Um dos personagens importantes de Grande sertão: veredas, de Guimarães Rosa, obra-prima da literatura brasileira e universal, é Zé Bebelo. Em determinado momento fica desorientado, perdido, sem iniciativa e sem saber o que fazer. E então diz o narrador: "Sempre Zé Bebelo não desistia de palavrear, a realização de projetos, como faz-de-conta. A mó de moinho que, nela não caindo o que moer, mói assim mesmo, si mesma, mói, mói" (G.s.: v., p. 306). Ele começa um processo de estagnação e até de auto-destruição, tendo que abandonar o papel de chefe. O mesmo ocorre com um leitor que não lê. É como uma mó de moinho que nela não caindo o que moer, mói a si mesma... Vive, vegeta, mas não se realiza em suas possibilidades. Não adianta só falar, "palavrear" sem um crescimento e realização, sem moer e produzir-se. Normalmente as pessoas que nada têm a dizer de essencial são as que mais falam, mas repetindo sempre as mesmas coisas e idéias, com as mesmas expressões-clichês e jargões. Isso se dá 
muito com os meios de comunicação e especialmente com a televisão. Muita fala, fala, fala e quase não se aproveita nada. Não nutrem. A farinha e o pão serão de acordo com o grão, a leitura, os textos e sua qualidade. A leitura é o grão que o moinho da inteligência e da alma mói e transforma, transformando-se. Sem leitura não há crescimento. Como temos o hábito de comer devemos ter também o de ler, tão essencial e vital este como aquele.

\section{O leitor com a cabeça cheia}

Vivemos hoje numa sociedade da informação e do conhecimento e temos que estudar muito. Por isso pode ocorrer a situação inversa da anterior: lermos demais sem critérios e distinções críticas, sem que seja algo essencial. É como se alimentar sem qualidade. Devemos buscar a harmonia do corpo e do espírito, que é um ser só. Este ideal é difícil de realizar cada vez mais. Houve um autor francês, Rabelais, que criou um personagem famoso, Gargantua, através do qual criticou o decorar muito e ter muitos conhecimentos sem qualidade. Por isso dizia que não é preciso ter uma cabeça muito cheia, mas bem feita. A televisão, os jornais, as revistas, os filmes de divertimento etc. etc. nos oferecem um mundo sem fim de informações e conhecimentos. E além disso ainda há dezenas de disciplinas e um número cada vez um maior de especializações. Diante de tantos conhecimentos pode nos surgir uma angústia muito grande, porque eles crescem em proporção geométrica, tornando obsoletos hoje os conhecimentos de ontem. E pode-se dar uma inversão: o conhecimento e sua procura tomar todo nosso tempo, ficando sem tempo para ser o que se conhece. Nesse sentido, os conhecimentos exercem uma grande violência, passando a dominar o ser humano e não operando a sua livre manifestação. Em vez de libertarem, aprisionam. Mas, inversamente, quem não se atualiza e se dedica ao estudo contínuo, fica excluído em meio à sociedade constituída e dominada pelos conhecimentos.

Como agir nesse caso? Como ter uma cabeça bem feita e não apenas cheia? Como escolher? São perguntas muito difíceis de responder. Simplesmente porque não há fórmula, regra ou receita. Nossa época é uma das mais radicais nas transformações, nos desafios para os jovens. E cada vez é maior o lugar e a importância da leitura para uma adequada e real formação, não só profis- 
sional e intelectual, mas também humana. Isso não significa uma cabeça muito cheia, sobretudo de leituras com informações e conhecimentos sem importância.

\section{Ler e reler}

Porém, como começar? Lendo. Para tal não há introdução, porque só podemos ser introduzidos naquilo que já vivemos e experienciamos desde sempre, desde que nascemos: ser sendo (ente). Contudo, deve-se partir de algo bastante evidente. A palavra, que é múltipla em seus significados e sentidos, tende a se fazer presente nos textos de diferentes formas: como imagenspoéticas, como questões, como conceitos. Estes, quando muito repetidos pelo uso cotidiano e até secular, se tornam clichês e jargões. É a língua comunicativa: simplória, direta, pobre, repetida, banal. Se o texto é feito de clichês, torna-se um alimento muito pobre. Se com muitas imagens-questões e questões mostra uma grande riqueza e possibilidades imensas de metabolização. Para que o ler não se torne inacessível e muito difícil, o leitor deve encarar essas dificuldades com naturalidade, partindo dos significados mais repetidos e simples para os mais ricos e complexos. Mas jamais deve abrir mão da reflexão, da metabolização das palavras e seus sentidos. É aqui que o uso do dicionário, do diálogo com a memória histórica e o procurar bons interlocutores ajuda muito. O crescimento, embora lento, virá naturalmente. Para isso, uma leitura de obras variadas e de diferentes épocas e autores ajuda muito. Contudo, dos comprovadamente bons, que passaram pela prova do tempo. E mais importante será, sem dúvida nenhuma, a repetição das leituras da mesma obra. Com certeza, cada um elegerá suas obras preferidas. E aí se faz uma ação realmente essencial: reler, reler. Re-ler ou imediatamente ou depois de algum tempo, será certamente uma experiência que trará muitas surpresas. As grandes obras, seculares, multisseculares e até milenares, são sempre origem de muitas falas e silêncios. Dentro do possível, como a alimentação,

O assimilar as idéias dos outros e repeti-las de modo próprio ainda não significa tudo. A esse processo se chamou tradicionalmente elaboração gramatical e uso retórico da linguagem. Essa elaboração se dá num processo misto de leituras, raciocínio e apropriação da memória da linguagem. 


\section{Ser poeta}

Há, contudo, um nível mais radical de expressão e de escrita: a poética. Mas esta, embora pressupondo a anterior, já não depende de uma vontade lógica e expressiva, do domínio gramatical e retórico. Vai além. Ela se dá num apelo e chamado de escuta, a que, muitas vezes, alguns até tendem a resistir. Contudo, dáse num apelo tão forte que não há outro jeito senão obedecer. Obedecer é um ob-audire: ob, diante de; audire: ouvir, ou seja, obedecer é um dispor-se para o ouvir. Ouvir o quê? A escuta do ser que somos. Tal fala se refere a uma imagem-questão tradicional: as Musas. Elas se fazem presentes de muitas maneiras. Um exemplo claro e elucidativo é a abertura do primeiro poema do primeiro livro publicado por Carlos Drummond de Andrade, Alguma poesia, onde diz no Poema das sete faces:

Quando nasci, um anjo torto,

Desses que vivem na sombra

disse: Vai, Carlos!, ser gauche na vida.

Anjo - mensageiro, angelos -, do verbo grego, angelein, o anunciar, remete aí para a fala que lhe chega num anúncio e fala imperativos, aos quais o poeta obedece, porque aberto para a escuta da fala das Musas, filhas de Mnemósine, a Memória. Contudo, a imagem-questão é aí muito ambígua, porque o anjo, portador das mensagens como luz e verdade, no poema vive nas sombras e em relação à verdade é torto. Já a imagem-questão, atribuída ao poeta, gauche indica claramente o estar à margem do sistema retórico-gramatical e das luzes fáceis do consenso social uniforme e dos sistemas institucionalizados. Como tal não escreverá verdades clichês e jargões, mas não-verdades, a verdade poética, escuta da fala do anjo das sombras e torto. Numa tal dimensão, escrever é mais do que expressar-se, é ser poeta. Quem se predispõe à escuta e à obediência do que somos como manifestações do ser-tempo e apelo da linguagem, enquanto poiesis como essência e sentido do agir? A violência da fala, pelo seu predomínio quase absoluto em nossa sociedade, é muito forte. Quem se dispõe a ler como escuta de Mnemósine, a memória do que fomos, somos e seremos? Quem se dispõe para a não-verdade de toda poiesis? 


\section{O leitor com a cabeça bem feita}

O leitor com a cabeça feita não é o mesmo que o leitor com a cabeça bem feita, isto é, a que se está fazendo sempre com reflexão, distinções críticas, aprofundamento, riqueza, exercício de libertação. Cada um deve logo começar a separar, a ler o que é essencial e a empregar muito bem o seu tempo. Para isso é necessário distinguir com critério o que é mera informação descartável, o que é conhecimento importante para a profissão que cada um escolher e o que é realmente fundamental para a realização do que é. Ocorre que hoje em dia cada vez mais há uma separação entre o que se conhece como profissão e o que se é. Como conciliar? Como não separar? Como haver uma harmonia? Nossa sociedade exige tantas funções mecânicas que fica muito difícil achar sentido e realização nelas como trabalho. O trabalho é uma das formas de agir pelo qual damos sentido a nossa vida. Mas, fique certo, leitor, isso é possível. Como? Realmente não há receita. E ainda bem, porque cada um é um projeto de ser e não apenas um ser programado e já pronto pelo código genético. Até porque o código genético nos oferece possibilidades, que realizamos ou não. Somos mais do que código, somos linguagem. E isso compete a nós, com nossas escutas e escolhas, nossas leituras.

\section{O leitor e a sabedoria}

À reunião de informações com conhecimentos sendo o que se é se chama, sempre se chamou: sabedoria. A sabedoria e o ser não se podem transmitir nem ensinar, só experienciar o sabor da sabedoria de ser. Ser sábio é ser, onde se sabe o sabor de ser. E isso nos é dito num poema síntese, pequena e preciosa jóia, de Fernando Pessoa/Ricardo Reis. Escutemo-lo.

Para ser grande, sê inteiro: nada

Teu exagera ou exclui.

Sê todo em cada coisa. Põe quanto és

No mínimo que fazes.

Assim em cada lago a lua toda

Brilha, porque alta vive. 
O verbo central do poema é ser. Em seis versos, aparece repetido quatro vezes, sendo duas no imperativo, verso $1:$... sê inteiro... e no verso 3: Sê todo...Três vezes ele está seguido de determinativos, de modos de ser, estabelecendo uma relação complementar para o que entende por ser: ser grande, sê inteiro, sê todo. Grande, inteiro e todo é o horizonte em que se projeta o apelo de ser, no poema, para cada um de nós, um apelo que nos vem do próprio ser que já desde sempre somos e não somos. O ser grande não é aí quantitativo nem tem valor moral nem significa poder. O grande está na simplicidade da inteireza, do ser inteiro, na medida em que se é integral e totalmente a porção, a cada um destinada como destino, o presente do ser que cada um recebe para ser. Grande e inteiro se implicam na dimensão do ser, para além das medidas do ter como quantidade e qualidade. Ser grande e inteiro é simplesmente ser o que ainda não se é. Isso se manifesta e apropria no agir enquanto sentido do que somos, ou seja, na poíesis. Apropriar não é ter, mas ser grande, completo, pleno, inteiro, íntegro.

Podemos numa primeira conclusão dizer que a questão central deste poema é o apelo para sermos o ser que somos, mas ainda não somos. Este desabrochar integral do ser que ainda não somos pressupõe algumas atitudes fundamentais. E o poeta as anuncia: Nada teu exagera ou exclui. O nada indica aí claramente um assumir integral e sem divisões o que somos, mesmo que a vida se dê em tensões aparentemente opostas. O exagerar ou excluir estão profundamente ligados ao sentido do agir. Ser é agir, mas dentro de uma escolha, em que não pode haver nem o querer ultrapassar o que nos foi dado para ser, nem excluir. Isto pressupõe uma tensão muito grande entre o limite e o não-limite. Como saber o que é exagerado? Haveria aí o perigo da hamartia, a desmedida? Não nos podemos projetar comandados pela nossa vontade, pelos nossos desejos, pois não somos sujeitos de nada. Por isso nos é feito o apelo imperativo, ser é sempre imperativo, de agirmos sempre dentro do vigor do que somos, sem exageros. Também não devemos excluir nada. O ser integra matéria e espírito, pequeno e grande, simples e complexo, e assim por diante. Porém, sempre realizado no e pelo sentido do agir. Por outro lado, uma falsa modéstia e humildade ou orgulho e empáfia em nada ajudam. Ser simples não é ser simplório, é simplesmente ser. Devemos nos apropriar do 
que nos é próprio. Só assim seremos o nosso destino. Nesse e só nesse sentido temos vontade: querer ser. Esse é o nosso horizonte para o qual, sem exageros e nem exclusões, nos devemos projetar. Ser deve sempre ser o penhor de nossos empenhos.

Numa sociedade de consumo de informações, conhecimentos, produtos, falas e vivências, manter a escuta silenciosa e paciente desse apelo é muito difícil. Contudo, esse é o nosso grande desafio. Nesse e só nesse sentido não devemos cair em tentação, Por isso o poeta reitera o imperativo para ser: Sê todo em cada coisa (v.3). Cada ação, cada escolha, cada decisão deve nos envolver todo. E então as ações, as atitudes e as coisas não serão algo que temos, mas algo que seremos. Cada ação deve, pois, nos envolver de uma tal maneira que seja um ato de desvelo, amor e de doação em que a escolha colhe, recolhe e acolhe o único necessário e integral, o inteiro: o ser. De tal maneira que eu possa sempre dizer: sou, a partir da escuta do ser que sou. Ser não pode ser medido pelo que os outros dizem ou esperam de nós nem pelo que a nossa vontade ou desejo projeta, tendo como modelo um ser ideal ou um paradigma que nos vem de fora. O valor, o tamanho, o alcance de nosso agir sendo se dá pelo envolvimento e densidade que tem como medida o ser. Para isso e por isso o poeta introduz um novo verbo, também no imperativo, convocando-nos: Põe quanto és / No mínimo que fazes. Ser, já vimos, é agir e fazer, mas a intensidade e envolvimento não está no que tem valor para o "mundo" (sistema já feito) ou para os outros, para o que nos é externo e, sim, no pôr o que se é, seja no que for (qualquer ação). Aqui há um paradoxo ao qual devemos prestar atenção. Pôr pressupõe sempre um agir. Porém, este agir se, por um lado, manifesta o que ainda não somos, por outro, apenas manifesta o que já somos. Por isso ele vai estar presente mesmo nas mais ínfimas ações, no mínimo que se fizer. Ora, este paradoxo apenas nos assinala algo verdadeiro, em termos de ser: cada um é um ente: é isto, é aquilo, é alto, é baixo, é inteligente, é simples, é ... sempre é, e ao mesmo tempo não-é, pois está sendo.

Nenhum ente é igual, cada um é uma doação original absoluta do ser, porque só podemos ser este ou aquele ente a partir do ser. Por isso somos sendo, isto é, provimos e nos presentificamos como doação do ser e caminhamos para o ser, num processo de manifestação e apropriação do que somos dimensionando-nos pelo ser e só pelo ser, ou seja, ser é: sersendo pelo agir e fazer até 
o sendoser. É a nossa medida essencial e única. Por que sersendo e sendoser? Ente não é um substantivo, se dimensionado pelo ser e não classificado por um pensamento gramatical vazio e formal, metafísico. Ente é verbo, ação, realização. E o verbo de todos os verbos é o ser. Como a gramática o pode classificar como mero verbo de ligação? Quem dizendo sou, se reduz a um verbo de ligação? Daí ser melhor dizer em lugar de ente, a palavra verbal: sendo. Contudo, este agir do sendo de cada ente não provém da vontade de cada um, mas do vigor da poíesis enquanto essência do agir. O vigor poético de realização provém única e exclusivamente do ser como poíesis. Por isso o pôr e o fazer só podem acontecer se optamos em ser a partir do ser. Porém, aí podemos perguntar: Como podemos sersendo se vigoramos já desde sempre no ser? Porque somos e não-somos. Porque o ser não-é: dá-se. Dá-se como ente e vela-se como ser. O ente como sersendo só pode estarsendo porque ainda não-é e se manifesta na e como ação, poíesis. O máximo, pois, de nossa vontade e liberdade é ser este não-ser. E nisso consiste a essência do sentido de nosso agir. Nisso e só nisso consistem as escolhas essenciais das leituras. Não devem, pois, ser quantitativas, mas qualitativas, essenciais.

\section{Ser e tempo}

Nosso projeto de ser se dá como tempo e linguagem. A vida vivida como experienciação de ser é o tempo como linguagem. A linguagem é o tempo maduro para a manifestação do que somos. A esse tempo os gregos deram o nome de Kairós: é o tempo oportuno, o tempo do florescimento e maturação, da eclosão do que somos. Cada um tem o seu Kairós. Para ser. Ser é o único desafio verdadeiro de nossa vida. Então esse é o horizonte de nossas escolhas e leituras. Não podemos exagerar nem excluir nada. Mas também não podemos perder tempo com bobagens ou ficar à toa. Isso significa viver em plenitude em tudo que fazemos. "Sê todo em cada coisa". Isso exige de nós uma grande atenção, um esforço para além do que "gosto ou não gosto", da minha vontade ou desejo de sujeito. O único desejo essencial é ser. Para isso "Põe quanto és / No mínimo que fazes". Não somos sujeitos, porque o ser nos foi dado, o verdadeiro sujeito. Não dependeu nem depende de nossa vontade. E somos sendo o que somos, o que nos foi dado: é nossa única e essencial pro-cura, o cuidado de ser. E tudo 
o mais virá por acréscimo. Seremos realmente inteiros. O que é ser inteiro? É ser único, algo inigualável, completo, assim como uma "lua" que brilha em cada lago, plena, porque alta vive a partir do ser, do sol.

\section{O ler e o logos}

Por que o ler tem essa força toda e se pode tornar o alimento mais essencial de nossa vida? Ler não é simplesmente a decodificação de signos escritos. Ler vem do legere latino e do lógos grego. Este significa o propor, o reunir no e como dizer. Logos é palavra, ação, manifestação, linguagem, língua escrita ou falada, poíesis. Por isso nos diz o poeta, no poema Procura da poesia:

Chega mais perto e contempla as palavras

cada uma

tem mil faces sob a face neutra ...

Essas "mil faces" da palavra são o alimento vivo, diferente, originário de que cada leitor em cada leitura pode-se apropriar, e por este se transfigurar. Para isso é necessário ler como escuta, visão e proximidade. É o que o poeta Carlos Drummond de Andrade nos convida a fazer, quando diz, no imperativo poético de seu poema:

\section{Chega mais perto e contempla as palavras}

Ler, como linguagem, é o sentir como experienciação o sentido do que somos. E isso nos advém em todas as manifestações poético-artísticas: música, pintura, cinema etc. etc. Isso nada tem a ver nem com manipulações estético-formais ou doutrinamento ideológico. Esse ler nunca pode ser um doutrinamento, mas sempre um alimentar-se para ser plenamente. Tal ler se dá como um caminho em que buscamos o que somos e não-somos. Porque o ser que somos e não-somos é um grande mistério e se nos presenteia e doa no questionamento. Neste consiste a descoberta inaugural e o desafio incessante do viver. 


\section{O ler e o real}

A ciência e alguns teóricos desavisados alardeiam que a arte da palavra é ficção, que não é real e que serve para a fruição pessoal, para divertir, para "passar tempo". Isso é falso. Não há nada mais real e profundo do que a poesia, a grande poesia. Esta é ação. Ela nos fala, nos leva à escuta do que somos. Ela nos propõe sempre imagens-questões a partir das quais nos alimentamos para desabrochar no que somos: sermos inteiros. E isso é ser real, o único real verdadeiro e fundamental.

\section{A leitura e a vida}

Alguns são obrigados a ler profissionalmente. Outros não. Seja como for, nunca se deve deixar de ler. Criar esse hábito não só nos alimenta e enriquece, proporcionando-nos momentos inesquecíveis de sedução, envolvimento, prazer e realização. Também pode ser um excelente remédio para horas indesejadas e difíceis. Como quando nos achamos em solidão. Alguém que está só e tem o hábito de ler e um bom livro à mão, tornará a solidão, muitas vezes, até um tempo oportuno, para lendo, descobrir que a solidão é ser solidário com os outros pelo diálogo (em silêncio), que somos uma grande co-letividade originária. Na leitura das grandes obras damos um grande mergulho em nós mesmos e através da reflexão aprendemos muito sobre os outros e muito mais sobre nós. Os limites do ser humano são insondáveis. E do sofrimento, na leitura e com a leitura, podem surgir grandes alegrias. Alguém que tem o hábito de leitura, de leituras substanciais, poderá viver intensamente e amenizar os sofrimentos, e fazer da solidão do limite uma convivência inimaginável. (O eu e o outro sempre nos advêm como limites, do que são e não-são). E mais: a vida se intensifica e densifica. E até algo surpreendente pode acontecer: vivermos mais, porque a atividade intelectual nos ativa o organismo e o espírito, e nossa memória se mantém viva. Nosso organismo se regenera e recebe seu vigor do que há de interior como o que somos.

\section{A leitura e a memória}

A linguagem é a "arte culinária" do ser de cada um. Ela é nosso ser, nossa memória. Somos sempre memória. Esta é o que 
há de mais enigmático em nossa vida. Não é um eu-superficial nem um eu-profundo. Não há eu: há ser, há memória. E o mito na imagem-questão Mnemósine, já nos disse originariamente o que ela é: o que foi, é e será. Adentrar a memória como consciência e sonhos ainda não é tudo. É necessário escuta e silêncio, evitando todo falatório e pretensões representacionais e conceituais.

Só podemos saber que há memória genética e conhecer em parte o código genético porque somos linguagem e memória. A memória nos chega como linguagem. Porém, nós não sabemos o que ela é. Nem carece. Basta ser. O ser não é, se dá: linguagem. O ser se diz: linguagem. A linguagem se dá: ser-memória. O ser é memória e por isso esta é o que há de mais misterioso em nós. A leitura do silêncio das grandes obras, e são grandes pelo silêncio em seu vigor máximo, abre a possibilidade de tecer a realização do que somos. A leitura nos permite recuperar como memória o tempo aparentemente perdido, e que está presentificado e vivo como memória da linguagem das, nas e como obras de arte, da poesia. Uma tal memória se dá e presentifica como visão, som, cheiro, gosto, tato. É o sentido dos sentidos. É a poiesis.

\section{Ler é dizer: eu sou}

Ler é alimentar-se da e pela memória do que já desde sempre somos.

Ser é o que há de mais autêntico, íntimo, profundo, imediato, evidente em cada um. O dizer mais radical e essencial é: eu sou. Onde o sou é que é a fonte originária de todo eu, de toda subjetividade. Mas também o mais misterioso. O hábito das leituras essenciais nos predispõe para a escuta do seu silêncio, do seu mistério.

Por que ler? Porque pode ser o alimento do ser que cada um é e o alimento de que necessita

Para ser grande... 


\begin{abstract}
In the actual built upon the writing and its representation as is ours, it is important not only knowing to read, but also creating the habit of reading. Nevertheless, which is the purpose on reading? This is as if feeding and making the art of one who reads an appropriable metabolism. It is developed in the following topics : the reader without reading; reading as an act of listening; the reader with a filled up mind; to read and to write ; being a poet; the thoughtful reader, the reader and the wisdom; reading and life; reading and the memory; reading and death.
\end{abstract}

KEY WORDS: reading, wisdom, memory, death, being.

\title{
Referências
}

ROSA, João Guimarães. Grande sertão: veredas. 6.e. Rio de Janeiro: José Olympio, 1968.

ANDRADE, Carlos Drummond de. Reunião. 4.e. Rio de Janeiro, José Olympio, 1973.

PESSOA, Fernando. Obra poética.. Rio de Janeiro, Aguilar, 1965. 